\title{
Analysis of Addax-Sinopec Outdoor Pathloss Behavior for WiFi and WiMAX Infrastructure
}

\author{
G. N. Ezeh \\ Dept. of Electrical/Electronic \\ Engineering, Federal \\ University of Technology \\ Owerri, P.M.B 1526, Owerri, \\ Imo State, Nigeria
}

\author{
U. O. Nwogu \\ Dept. of Electrical/Electronic \\ Engineering, Federal \\ University of Technology \\ Owerri, P.M.B 1526, Owerri, \\ Imo State, Nigeria
}

\author{
K. C. Okafor \\ Dept. of Electrical/Electronic \\ Engineering, Federal \\ University of Technology \\ Owerri, P.M.B 1526, Owerri, \\ Imo State, Nigeria
}

\begin{abstract}
In wireless environments, improper handover among mobile terminals can occur during micromobility due to various reasons. Once this takes place, the network Quality of Service (QoS) experiences degradation thereby increasing the call drop rate, creating latency problems and decreasing throughput. In such scenario, there is an urgent need to optimize network performance while utilizing network resources efficiently. Interestingly, various pathloss methods have been recently proposed to achieve relative network performance but these methods have high complexity and are cost effective. This work applied Hata model in spatial micromobility environment to evaluate the performance of mobile wireless access within Wifi and WiMax infrastructures. The work used Addax-Sinopec petroleum, a drilled deep exploratory oil well in Izombe, Oguta Local Government area situated in the south eastern part of Nigeria as a study testbed. From the testbed, technical data were collected for both a dedicated Wifi hotspot and Globacom WiMax infrastructure. The Wifi Tiplink access point, WiMax Distributed Control System (DCS) and a wireless router were all configured for the initial pathloss experimentation. MATLAB Script was developed for evaluation purposes considering the testbed. The results of the comparison show that WiMax offered a lower pathloss value compared with Wifi-network WiMax (IEEE 802.16). This makes WiMax optimal for wireless access communication with advantages such as being flexible, having long range, and offering high data capability.
\end{abstract}

\section{General Terms}

Macromobility, Wireless Networks, Network Scenario, Hotspots, Long Range communication Network.

\section{Keywords}

Wifi, WiMax, Mobility, Pathloss, QoS, Signal Degradation, Latency, Call drop rate

\section{INTRODUCTION}

\subsection{Background of Study}

Wireless fidelity (Wifi) and Worldwide Interoperability for Micro Wave Access (WiMax) are broadband wireless technologies that could offer broadband experience in wireless environments. These are designed to accommodate both fixed and mobile broadband applications. However, the wireless broadband technologies were developed with the aim of providing services comparable to those provided to the wire line networks. Cellular networks now provide support for high bandwidth data transfer for numerous mobile users simultaneously [1],[2]. First, there several benefits derived from these technologies which include: elimination of Digital subscriber line (DSL) technology which provides broadband services over twisted pair wire. It also eradicates the use of cable-modem technology which transmits traffic over a coaxial cable, thereby eliminating this expensive and high infrastructural technology [3].

In the case of wireless technology, this can very beneficial in rural areas and some other environments that lack the capacity to afford wired infrastructure for broadband access. Generally, the attractiveness of wireless networks is attributed to their characteristics such as ability for infrastructure-less setup, minimal or no reliance on network planning and the ability of the nodes to self-organize and self-configure without the involvement of a centralized network manager, router, access point or a switch. These features help to set up a network fast in situations where there is no existing network setup or in times when setting up a fixed infrastructure network is considered infeasible, for example, in times of emergency or during relief operations [3].

Granting that WiMax is a broad band wireless technology which brings broadband experience in a wireless context, it is pertinent to note that a lot of broadband wireless technologies and standards exist and have evolved over time to solve most interoperability problem. Such standards include: Worldwide interoperability for microware access (WiMax), Wireless Fidelity Technology (Wifi), the GSM technology, CDMA (Code Division Multiple Access) and the UMTS (Universal Mobile Telecommunication System) [4]. The WiMax system takes care of wireless connectivity in and around a locality or city (WMAN). It involves all the equipment that meets the IEEE 802.16 family standards. On the other hand, the Wifi system takes care of wireless connectivity around a local Area Network environment (WLAN) e.g. house, office complex, hotels etc. Incidentally, these two networks experiences pathloss issues owing to location techniques used [5],[6]. In most of localization algorithms, the accuracy of onedimensional distance estimation, to a great extent, affects the performance of range-based localization systems just like in wireless sensor networks [5]. Pathloss challenges can be addressed with range free localization technologies, like scene analysis [7], APIT [8] and distance vector-hop (DV-HOP) [9]. These rarely need distance information for pathloss study as found in wireless sensor communication. However, one of them may be time consuming or require a symmetrical localization network [5]. In addition, the localization accuracy and cost may not fit for outdoor wireless location system. Therefore, range-free localization procedure is not optimal. Ranging approaches such as RSSI[10],[11],[12], Angle of Arrival (AOA) [13],[14], Time Difference of Arrival (TDOA) [15],[16], Time of arrival (TOA) [17], Lighthouse [18], Ultra wideband (UWB) [19], and other schemes have been widely 
used in a variety of ranging fields including in Wifi but not yet in WiMax domain. Each of these approaches has its own advantage sand disadvantages. Compared with RSSI-based methods, it is expensive for the approaches like AOA, TDOA and UWB to obtain the estimated distance for pathloss computation. Basically, AOA computation will require costly antenna arrays on each base station and TDOA is highly time synchronization demanded [5]. However, all these methods require special or costly hardware but can still be applied in required environments. The above approaches can be used to study the performance as well as the extent of pathloss between Wifi and WiMax micromobility environments. The interest of this work is to basically compute the pathloss models of Wifi and WiMax and carry out an evaluation to ascertain the best type of network for enterprise deployments.

\subsection{Motivation}

Most times in any wireless environment when there is improper handover among mobile terminals as they move across the wireless environment, this reduces the quality of service by increasing the call drop rate, creating latency problems and decreasing throughput. This improper handover or mobility among users in these environments could arise when the pathloss parameters are not properly computed and dully followed during the installation or implementation of the wireless access infrastructures. Consequently, this could grossly affect the QoS for mission critical wireless deployments. Again, location estimation for Wifi and WiMax deployment can contribute to signal degradation as well.

\subsection{Research Contribution}

This work used a range based Hata model (in a frequency range of $150-1800 \mathrm{MHz}$ for a distance of $100 \mathrm{~m}$ to $80 \mathrm{~km}$ ) to compute pathloss values and then compare these values for both Wifi and WiMax networks. Also, this work takes cognizance of the fact that the Wifi router frequency range is between $1800 \mathrm{MHZ}$ to $2000 \mathrm{MHZ}$ and covers a distance of up to $100 \mathrm{~m}$ while the WiMax equipment operates at a distance of up to $80 \mathrm{~km}$ with a frequency range of $2-11 \mathrm{GHz}$. Due to the relatively low data rate of WiMax equipment, the transmission path of Wifi router, must consider the specification range of WiMax equipment at the base station to enable proper handover. This is achieved by making sure that the power of the Wifi router to be used must be equal or above the calculated path-loss value to, enable proper mobility among users on the network environment. This also applies to the WiMax equipment at the base station. When the necessary path-loss calculations are done, the power level of the equipment to be used could be considered for performance enhancement.

The rest of the paper is organized as follows. Section 2 presents related works on pathloss effects in Wifi and WiMax respectively. In Section 3; a description of the research methodology was presented. Section 4 discussed the results analysis obtained from the Hata model. Section 5; presented the conclusions and future work.

\section{RELATED WORKS}

The author in [21] explained that there several models available to estimate the path loss, such as: COST 231-Hata model [21], Hata-Okumura model [22], COST 231 WalfishIkegami (W-I) Model [23], and Stanford University Interim model [24], among others. These have their respective application contexts. In [25], the authors simulated the propagation path loss models using MATLAB software. This was done based on the variation of the distance between the base station and the receiver in the range of $0.5 \mathrm{~km}$ to $5 \mathrm{~km}$, for different height of the receiver antenna 3,6 , and $10 \mathrm{~m}$, within the operating frequencies $2.5 \mathrm{GHz}$, and $3.5 \mathrm{GHz}$. Their results were compared and analysed to identify a suitable model in different environments.

In [26], the author performed site specific measurements which are essential for path loss prediction in a WiMax network operating at a frequency of $2.3 \mathrm{GHz}$ over a range of $100 \mathrm{~m}$ to $3 \mathrm{~km}$. The work in [27] described how Okumura Hata's model is chosen and optimized for urban outdoor coverage in the Code Division Multiple Access (CDMA) system operating in $800 \mathrm{MHz}$ UHF frequency band, Southsouth Nigeria. The work carried out empirical measurements in a CDMA network focusing on the city centre of Benin, Edo state. It is developed by comparing the calculated path loss from collected measurements with the well-known path loss models within applicable frequency range of CDMA system, such as Hata, SUI, Lee, and Egli's Model. The work concluded that this model could improve and would be more reliable to be applied in the Nigeria CDMA system for urban path loss calculation in the $800 \mathrm{MHz}$ frequency band. In [28], a similar measurement of signal strength of OFDM driven WiMax technology at $2.6 \mathrm{GHz}$ band was carried out. The results are analysed and compared with empirical path loss models such as Hata-Okumura, Modified Hata and COST231Hata. COST-231 model shows highest path loss for suburban environment.

For the purpose of this research, the use of standard range Hata model will be considered. This is due to their economy from the time and money perspective. Thus, the Hata model pathloss calculation was applied in this study since it could be used to calculate the pathloss at the frequency range for Wifi and WiMax wireless standards and takes readings for wireless infrastructure (fixed and mobile). It could also be applied in all the three wireless cell ranges viz: large cell (radius exceeding $1 \mathrm{~km}-3 \mathrm{~km})$, small cells $(1 \mathrm{~km}-3 \mathrm{~km})$ and micro cell $(100 \mathrm{~m}-300 \mathrm{~m})$.

\section{METHODOLOGY}

\subsection{Scenario Description}

This work used a testbed located in a flow station that has both Wifi and WiMax facilities for the pathloss investigations. First, in developing a wireless setup considering its power budget calculation, the work identified the need to establish a logical balance between the uplink and down link. With this, it then becomes possible to calculate the potential pathloss between signal base stations or between the transmitting and receiving antennas. To balance the uplink and down link, the power at the base transceiver station (BTS) have to be adjusted. Now, for a wireless communication network, this power balance between the uplink and down link determines the range of the cell. It was established in this research that the pathloss and signal strength are function of distance as shown in Fig.1a where, $\mathrm{Wx}_{1}=\mathrm{WiMax}$ coverage distance from Antenna while $\mathrm{Wf}_{1}=$ Wifi Router coverage distance from antenna. Figures $1 \mathrm{a}, 2 \mathrm{a}$, and $2 \mathrm{~b}$ shows the pathloss systems architecture/diagrams illustrating the contextual testbed in this work 


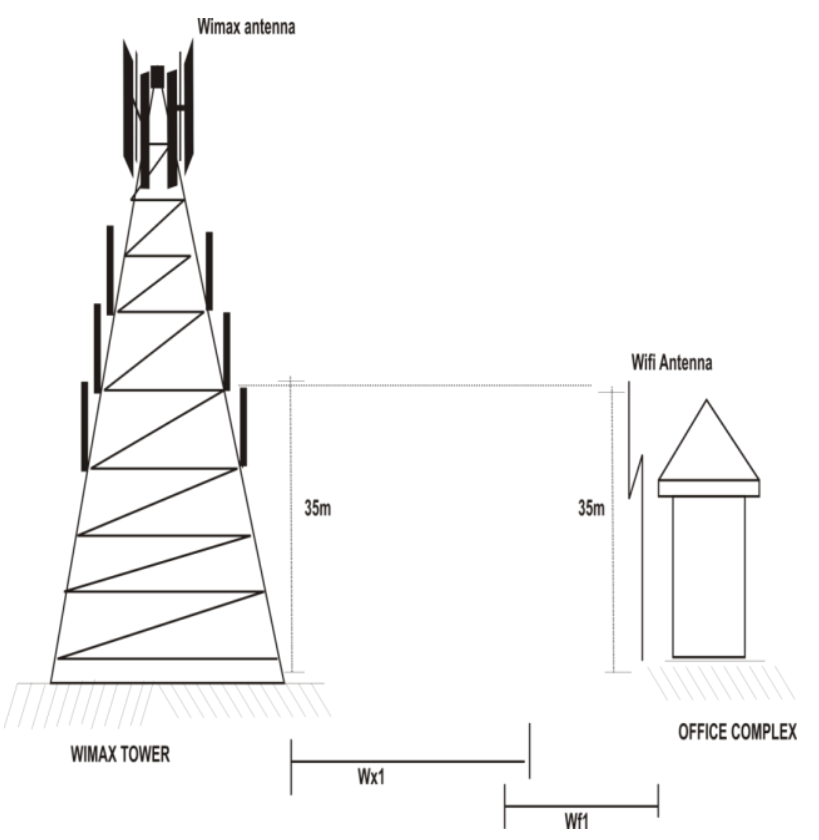

Fig 1a: Pathloss System Diagram

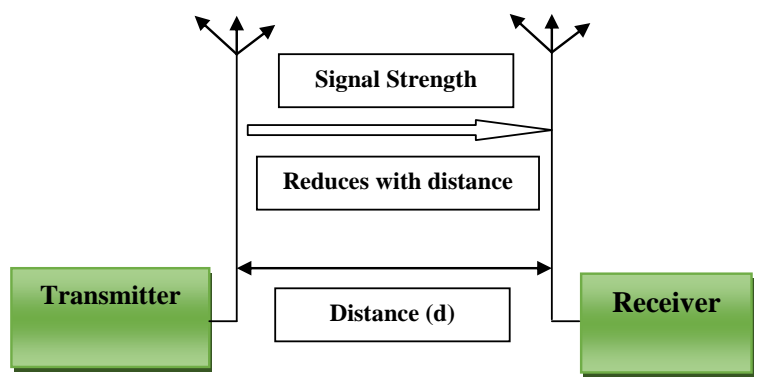

Fig 1b: A Typical Network Signal Pathloss

Now, from Fig.1a, and 1b, the awareness of the pathloss between the transmitting stations assists the network planners in determining the following:

- The frequency for signal to be radiated

- The distance at which the base stations will be separated

- The choice of antenna height

Hence, the pathloss between the transmitting and receiving antennas are to be calculated and compared at similar conditions using the Hata model. In this work, the Wifi router located around/within an office complex is used, where the frequency of the router, height above the ground level. The coverage radius and speed are used to compute the pathloss within the Wifi environment. Also the WiMax equipment at the cell's base station is studied and the above related information is collected, to compute for the pathloss around the wireless environment. As shown in Fig 2a, an improper handover or mobility around the area marked $X$ is experienced due to increase in pathloss. Mobile terminals (MT) around this area will experience call drops and other network malfunctions. This is a very serious observation for $35 \mathrm{~m}$ antenna heights depicted in Fig.2a

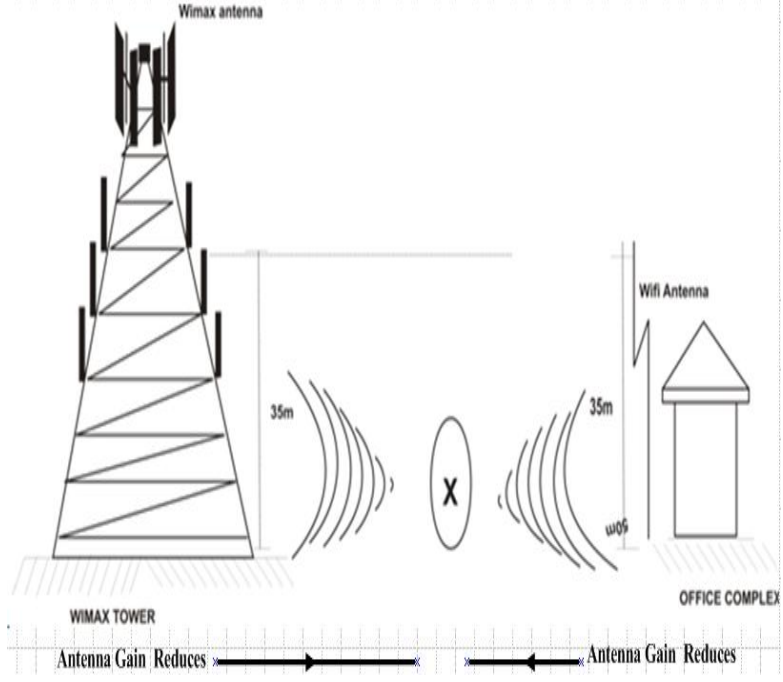

Fig 2a: High pathloss in area marked $X$

Fig $2 b$ illustrates a scenario where the pathloss is reduced, as such the area marked $X$ now experiences little or no call drops while latency problems fades off as the antenna heights of both the WiMax and Wifi equipment are increased. In this case the antenna heights are increased by additional 15 meters depicted in Fig.2b.

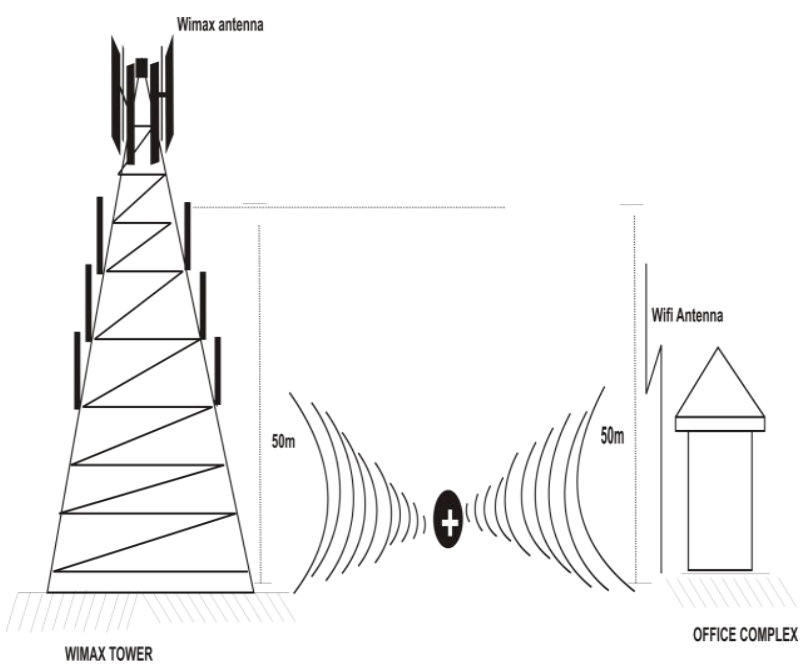

Fig.2b: Reduction in pathloss in area marked $X$

Fig 2c, illustrates an optimal or effective pathloss scenario. In this case, the antenna heights (for both Wifi and WiMax) were increased by 50 meters. It was observed that the area marked $X$ fades away completely. This shows that the pathloss is reduced tremendously as the antenna height increases. The implication is that mobility among MT's in and around the vicinity tends to be highly effective. Hence, the MT's would not experience network failure as they move within the cell area. This is the expected scenario for effective traffic propagation in wireless facilities. 


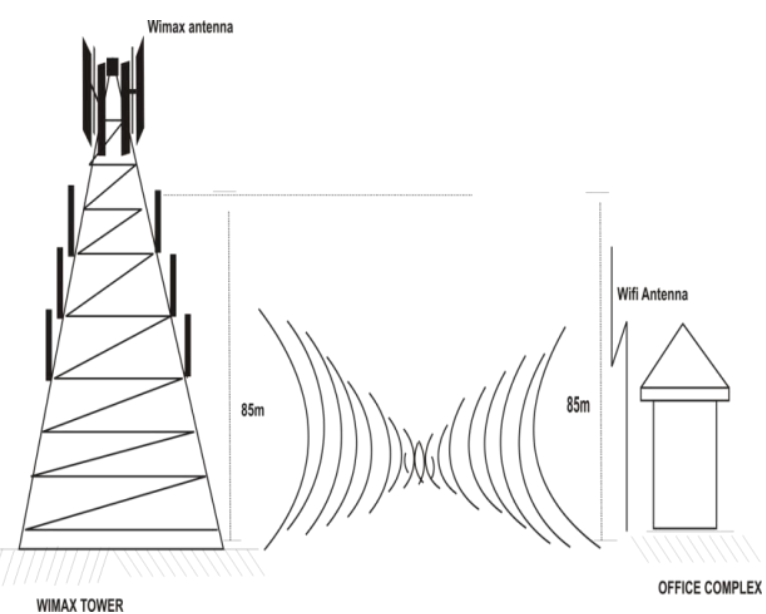

Fig 3: Optimal Pathloss Incidence (Area marked X fades away).

From the scenario description so far, this work will now present empirical calculation for the studied testbed so as to derive a valid justification for Wifi and WiMax pathloss behavior in this reearch.

\subsection{Pathloss Estimation with Hata Model}

The Hata model path loss calculation equation is given thus:

LP (urban) EDB $)=69.55+26.1 \log _{10}\left(\mathrm{f}_{\mathrm{c}}\right)-13.82 \log _{10}\left(\mathrm{~h}_{\mathrm{te}}\right)-\mathrm{A}$ $(\mathrm{hr})+\left(44.9-6.55 \log _{10}\left(\mathrm{~h}_{\mathrm{b}}\right) \log _{10}(\mathrm{~d})\right.$

Where

A (hr) is a correction factor for the receiving antenna height which depends on the size of the coverage area.

A $(\mathrm{hr})=3.2\left(\log 10(11.75 \mathrm{hre})^{2}-4.97 \mathrm{db}\right.$

Where,

From Equ.1 and 2,

Lp $($ urban $)=$ Pathloss at the urban,$H_{b}=$ base station antenna height, $H_{r}=$ receiving station antenna height

$F=$ frequency of signal radiation.

Now, the Hata model was in determining the path loss in Wi$\mathrm{Fi}$ and WiMax technology standards because of its convenience for frequency range of $150-15000 \mathrm{MHz}$ and for distance range of $1 \mathrm{~km}$ to $20 \mathrm{~km}$. This requires that the base station antenna height should be from $30 \mathrm{~m}$ and the receiving station antenna height of $3 \mathrm{~m}$ and above. It also gives room for correction factors inclusion in the model. The advantage of this model is that it offers a cost effective and time conserving approach to pathloss computation. This could be used before going ahead with the implementation of such systems. The calculation of the pathloss was part of the wireless system design procedure used to check how it could be used to improve mobility of mobile nodes within a wireless environment. The reason is to allow for better quality of services and improved network performance. Furthermore, the Hata model was used due to its economy from the time and money perspective.

\subsection{Data Collection Technique}

The data readings for wireless infrastructure (fixed and mobile) were taken using the Wifi router (TP LINK) located within an office complex (Addax Izombe) in Oguta local government area (LGA) of Imo state; suited in the south eastern part of Nigeria. This setup has a flow station which houses Wifi Internet facility and WiMax Globacom Digital Control Module which were adopted for this study. In this setting, the frequency of the router, height above the ground level, coverage radius and speed are used to compute the pathloss within the Wifi environment. Also the WiMax equipment (DCS module used by GLO GSM Network) at the cell's base station (at Izombe) were configured while obtaining the relevant data for compute the pathloss around the wireless environment. These are discussed next.

\subsubsection{Wi-Fi Network Hata Model for Estimation of Maximum Pathloss}

This work used the Wi-Fi technology (IEEE 802.11) support with a limited service range of about $100 \mathrm{~m}$. This was employed in the Hata model path loss equation in Equ 1 to compute the Wifi-pathloss value. Table1 shows the TP Link Wi-Fi Router parameters (IEEE $802.11 \mathrm{a} / \mathrm{b} / \mathrm{g} / \mathrm{n}$ ). This was obtained from the testbed environment.

Table 1: Micromobility Wifi-parameters (Source: TP LINK wireless router)

\begin{tabular}{|l|l|}
\hline Parameter & Value \\
\hline Frequency & $2.4-2.485 \mathrm{GHz}$ \\
\hline Speed & $300 \mathrm{mbps}$ \\
\hline Power & $700 \mathrm{Mw}$ \\
\hline Gain & $34 \mathrm{bB}$ \\
\hline $\begin{array}{l}\text { Interference margin } \\
\text { (IM) }\end{array}$ & $3 \mathrm{Db}$ \\
\hline $\begin{array}{l}\text { Distance from the } \\
\text { ground (Height te) }\end{array}$ & $10 \mathrm{ft}$ \\
\hline Coverage distance & $100 \mathrm{~m}$ \\
\hline
\end{tabular}

Using the Hata model path loss Equ in Equ 1, the parameters of Table 1 were substituted (i.e. the real values of the Wifi router), in order to calculate the pathoss. But, there is need to obtain the correction factor given by [7].

Now, the correction factor for the receiving antenna height $a(h r)[35 \mathrm{~m}]$, is obtained thus below.

$\mathrm{a}(\mathrm{hr})=3.2\left(\log \left(11.75(1.5)^{2}-4.97\right) \mathrm{dB}\right.$

$\mathrm{a}(\mathrm{hr})=3.2\left(\log (17.625)^{2}-4.97\right) \mathrm{dB}$

$\mathrm{a}(\mathrm{hr})=7.975-4.97 \approx 3 \mathrm{~dB}$

Substituting the a(hr value $=3 \mathrm{~dB})$ in Equ 1, the pathloss is now given thus;

$\mathrm{Lp}(\mathrm{dB})=69.55+26.16 \log 2400-13.82 \log (35)-3+(44.9-$ $6.55 \log (35) \log (0.1)$

Lp $(d B)=69.55+26.16(3.380)-13.82(1.544)-3+(44.9$ $6.55(1.544)(-1)$

$\mathrm{Lp}(\mathrm{dB})=157.97-18.3381+34.7868=174.4250 \mathrm{~dB}$.

Hence, the pathloss value, $\mathrm{Lp}(\mathrm{dB})$ gave $174.4250 \mathrm{~dB}$.

From the above, Wifi-pathloss calculated value, the physical interpretation shows that the maximum signal path loss experienced between the transmitting and receiving antennas, spaced $100 \mathrm{~m}$ in the Wi-Fi network is $174.4250 \mathrm{~dB}$.

Hence, in the course of signal radiation, the service provider must ensure that the power of the signal to be transmitted must exceed this figure $(\sim 174.4250 \mathrm{~dB})$ otherwise the transmitted signal must not be received by the receiving station. 


\subsubsection{WiMaX Network Hata Model For} Estimation of Maximum Pathloss

The pathloss for WiMax scenario is computed in this section. It should be noted that the WiMax technology (802.16) has a maximum service range of about $50 \mathrm{~km}$ (LOS). WiMax attains this long distance because it uses Orthogonal Frequency Division modulation (OFDM) scheme. Table 2 shows the parameters of WiMax Digital Control System (DCS) module used by GLO mobile communication.

Table 2: DCS WiMax parameters (Source: Glo Mobile Service Providers)

\begin{tabular}{|l|l|}
\hline Parameter & Value \\
\hline Frequency & $2-11 \mathrm{GHz}$ \\
\hline Speed & Up to $1 \mathrm{Gdps}$ \\
\hline Power & $35 \sim 40 \mathrm{~dB}$ \\
\hline Gain & $16 \mathrm{~dB} \sim 34 \mathrm{~dB}$ \\
\hline Coverage distance & $2.3 \mathrm{~km}$ \\
\hline $\begin{array}{l}\text { Distance between } \\
\text { networks (D) }\end{array}$ & $10.94 \mathrm{KHz}$ \\
\hline $\begin{array}{l}\text { Distance of the tower } \\
\text { /Antenna }\left(\mathrm{H}_{\text {re }}\right)\end{array}$ & $35 \mathrm{~m}$ \\
\hline
\end{tabular}

By computing the path loss using the Hata model for WiMax and inserting the parameter values of Table 2 in Equ 1, this was used to compute for WiMax pathloss value.

But, before computing for the pathloss model in WiMax scenario, there is need for the correction factor as depicted by Equ 2. Hence, by using the Hata model path loss calculation Equ 2, the correction factor for the receiving antenna height is computed thus, viz:

WiMax a(hr) $=3.2(\log (11.75(1.5) 2-4.97 \mathrm{db}$

WiMax a(hr) $=3.2(\log (17.625) 2-4.97 \mathrm{db}$

WiMax a $(\mathrm{hr})=3.2(\log 310.64)-4.97 \mathrm{db}$

WiMax a $(\mathrm{hr})=7.975-4.97=3 \mathrm{~dB}$.

With the WiMax a(hr) of $3 \mathrm{~dB}$, this was substituted into Equ 1 as shown below.

WiMax Lp $(\mathrm{db})=69.55+26.16 \log (900)-13.82 \log (35)-$ $3)+(44.9-6.55 \log (35) \log (2300)$

WiMax $\operatorname{Lp}(\mathrm{db})=69.55+26.16$ (2.954)- $13.82(1.544)-3+($ 44.9- 6.55 (1.544) (3.3617)

WiMax Lp $(\mathrm{db})=146.8266-18.3381+7.9025$

WiMax Lp $(\mathrm{db})=154.7291-18.3381$

WiMax $\operatorname{Lp}(\mathrm{db})=136.3910 \mathrm{~dB}$

The power levels were obtained for the transceiver equipment (Wifi- Router, WiMax- DCS) depending on the variations of the system parameter. Thus with proper design parameters, a good network environment could be created that will allow mobile subscribers move around the network sharing information with improved services and wireless proficiency. From this calculation, the WiMax $L p(\mathrm{db})$ physical explanation can now be discussed. In context, the maximum signal path loss experienced between the transmitting and receiving antennas, spaced $2300 \mathrm{~m}$ apart in the GLO WiMax network is $136.3910 \mathrm{~dB}$.

This coverage distance is about 23 times that of the Wi-Fi technology transmitting at frequency of $2400 \mathrm{MHz}$. In other words, for GLO WiMax technology with the service range of $2300 \mathrm{~m}$, and a Wi-Fi technology with the services range of $100 \mathrm{~m}$, the path loss experienced during signal transmission in the Wi-Fi network is greater than that in the WiMax network. Hence, to ensure that the signal radiated in the WiMax technology gets to the receiving stations antenna, the service provider must ensure that the power of the radiated signal must exceed $136.3910 \mathrm{~dB}$

\section{ANALYSIS OF RESULTS}

Having carried out initial link budget (ie. path loss calculations) at various $\mathrm{Wi}-\mathrm{Fi}$ and WiMax distances and constant antenna height, the following results were obtained graphically using MATLAB script M-file. Figures 4 shows that at a constant antenna height, the pathloss of a $\mathrm{WiFi}$ network increases as the distance traversed from 0 to $50 \mathrm{Km}$ within the WiFi cell domain.

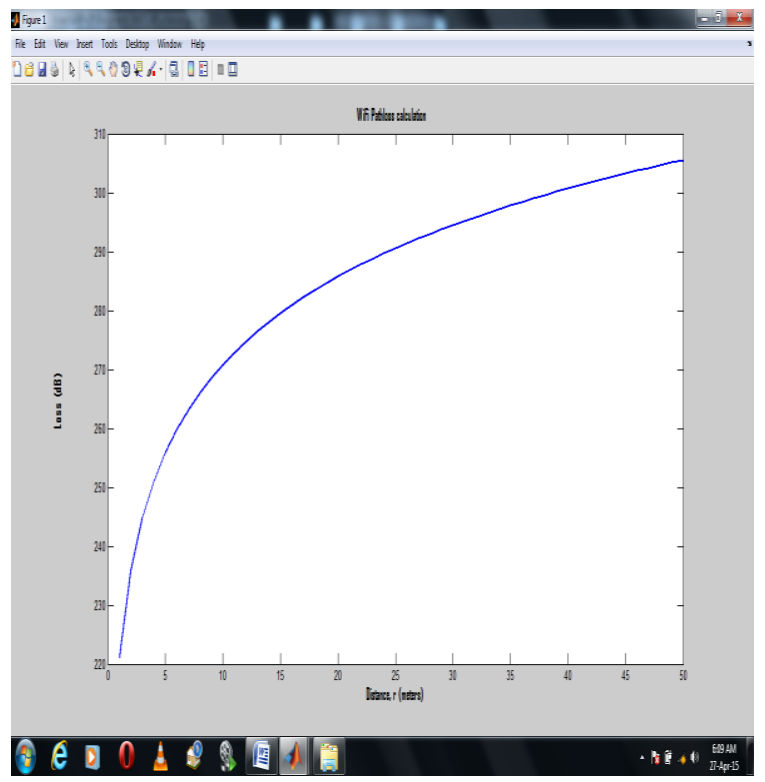

Fig.4: The plot of Wi-Fi Pathloss at a distance of 50m

Figure 5 shows that at a constant antenna height, the pathloss of a WiMax network increases as the distance traversed from 0 to $5000 \mathrm{~m}$ within the WiMax cell domain.

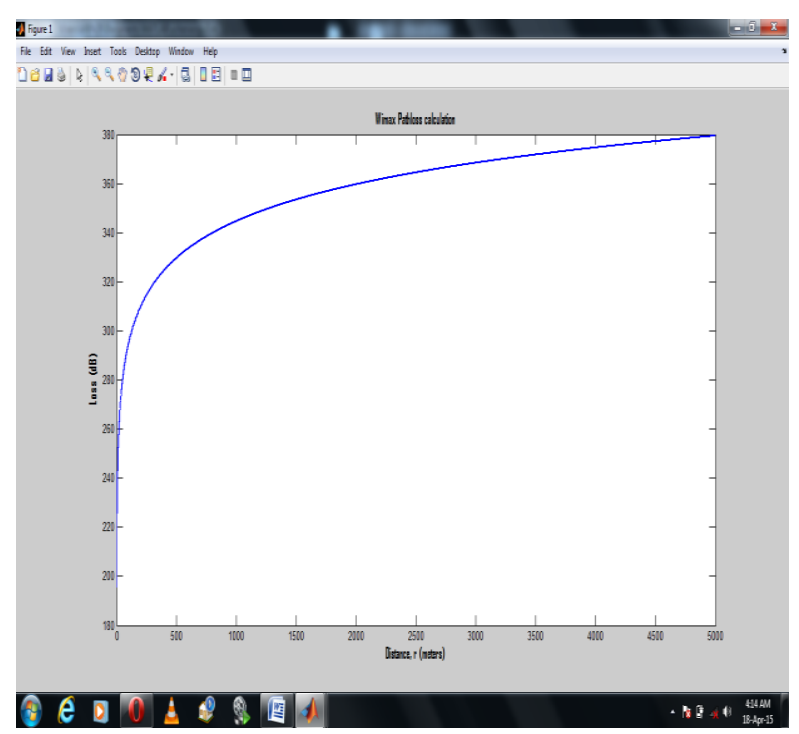

Fig 5: A plot of WiMax pathloss at a distance of $5000 \mathrm{~m}$

Figure 6 shows both WiFi and WiMax networks juxtaposed together. It was observed that over a distance of $500 \mathrm{~m}$ within a cell domain with both telecommunication standards, $\mathrm{WiFi}$ network experiences more signal degradation (pathloss) than 
the WiMax network. It shows that the WiMax signal can travel farther than the WiFi signal.

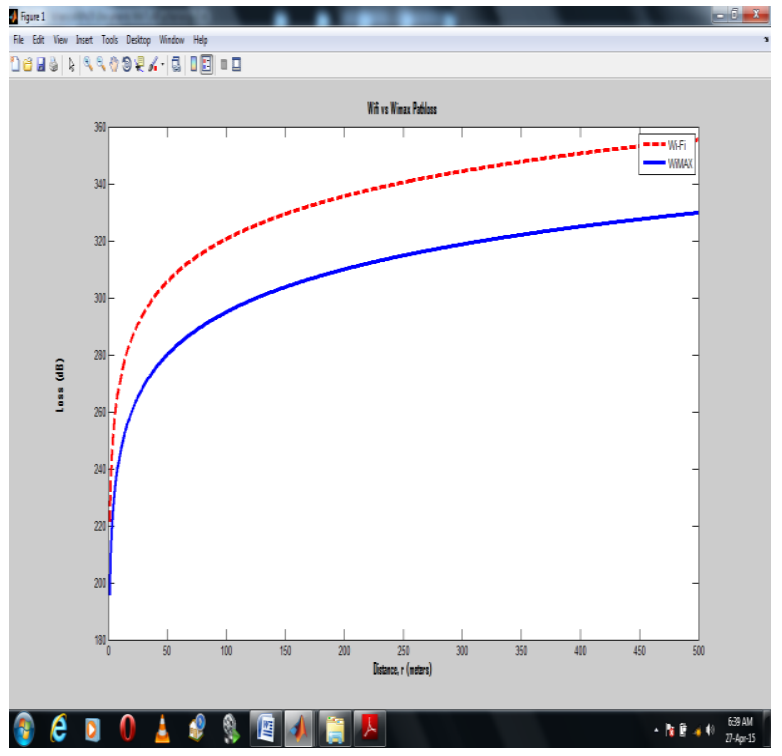

Fig.6: Wi-Fi Vs WiMax Pathloss at a distance of 500m

Figure 7 shows a bar chart plot of a WiFi network over a distance of $20 \mathrm{~m}$.It shows a higher pathloss over this distance for a WiFi network.

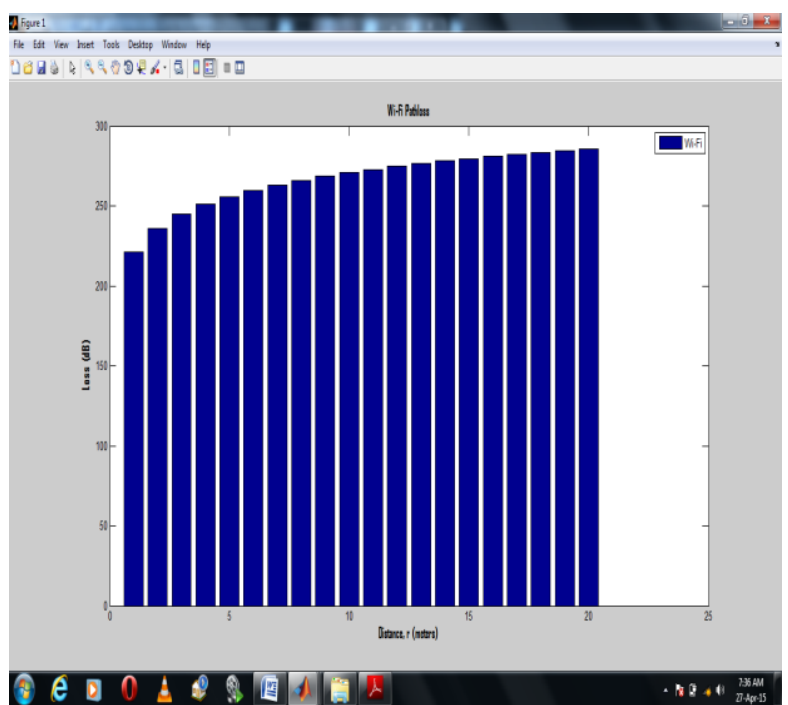

Fig.7: Bar plot of Wi-Fi Pathloss at a distance of $20 \mathrm{~m}$

Figure 8 shows a bar chart plot of a WiMax network over a distance of $20 \mathrm{~m}$. It shows a lower pathloss in the WiMax network as compared to the WiFi network

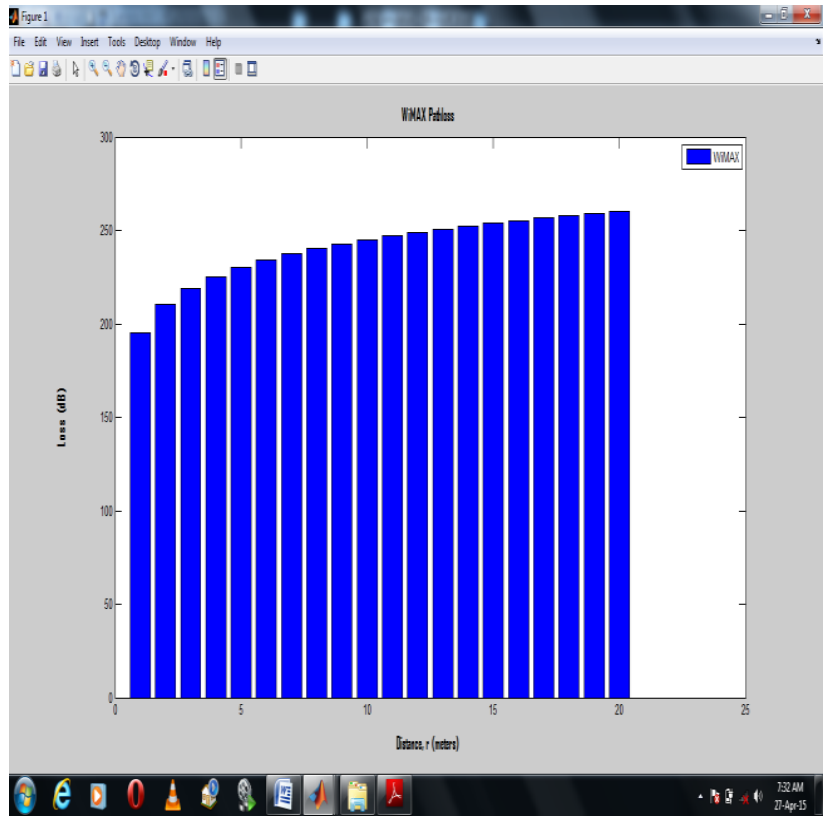

Fig.8: A Bar plot of WiMax Pathloss of equation at a distance of $20 \mathrm{~m}$

Figure 9 shows a both networks at the respective operating frequencies. It shows that even at $50 \mathrm{~m}$, the pathloss of the WiFi network is about $280 \mathrm{~dB}$, whereas at about the same distance in the WiMax network, the pathloss is lower.

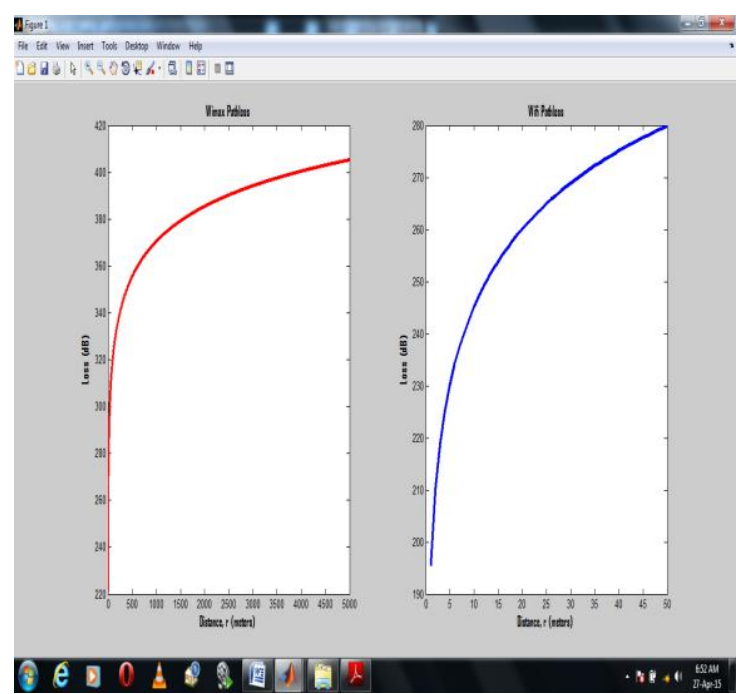

Fig. 9: WiMax vs Wi-Fi Pathloss plot at frequencies of 2.4 GHz and 900MHz respectively

Figure10 shows a WiFi plot at distance of $100 \mathrm{~m}$.it shows that with increasing distance, the pathloss increases considerably. 


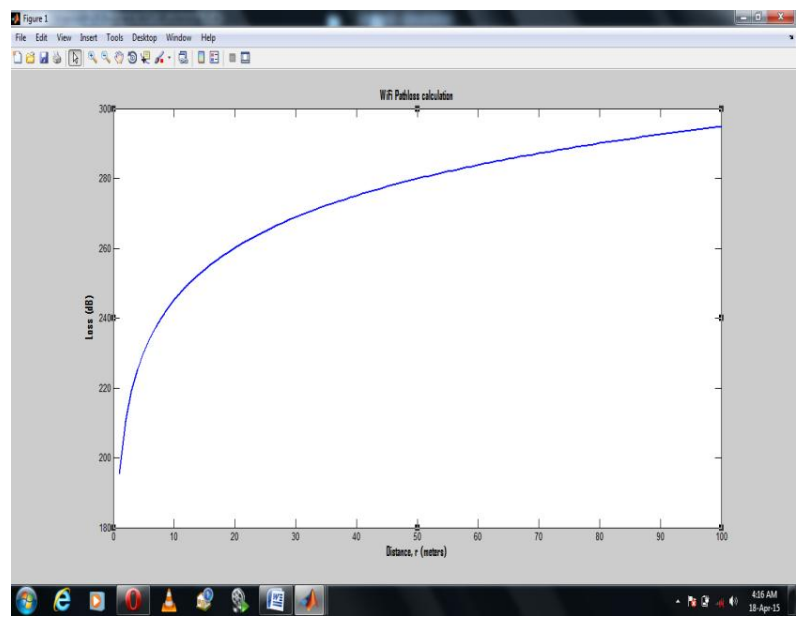

Fig.10: A plot of Wi-Fi Pathloss of equation at a distance of $100 \mathrm{~m}$

Fig.11 shows the WiFi plot at various distances of $5 \mathrm{~m}, 20 \mathrm{~m}$, $60 \mathrm{~m}, 100 \mathrm{~m}$ accordingly in the testbed setup.

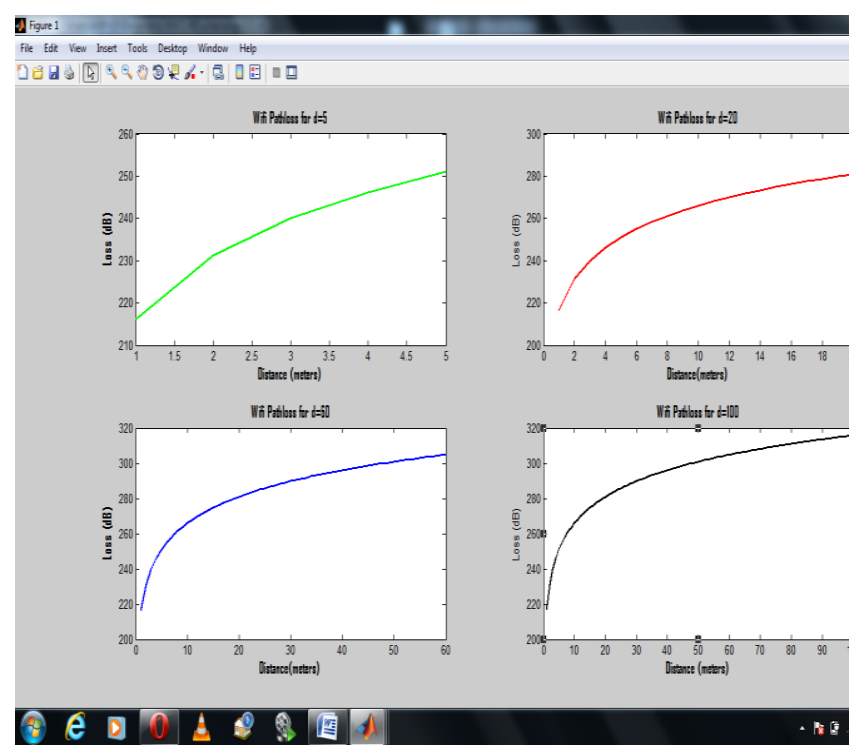

Fig.11: WiFi plot at various distances of $5 \mathrm{~m}, 20 \mathrm{~m}, 60 \mathrm{~m}$, $100 \mathrm{~m}$

\section{CONCLUSION}

This paper has presented a detailed computation and comparison on pathloss performance considering two emerging wireless technologies namely: Wi-Fi (IEEE 802.11), WiMax (IEEE 802.16). The study focused on micromobility management, pathloss calculations, and design requirements as they affect signal/call handover in a network. Technical data were collected for both of these technologies from the Globacom mobile network WiMax DCS and a wireless Router both in Addax-Sinopec Petroleum, Izombe testbed located approximately $25 \mathrm{~km}$ northwest of the Imo state capital Owerri, found on Latitude: $5^{\circ} 40^{\prime} 5.36 " \mathrm{~N}$; Longitude: $6^{\circ} 52^{\prime} 15.71$ "E. . The results of the comparison show that WiMax indicates the upcoming of the next wave of wireless access infrastructure as it gives less pathloss. WiMax technology has the main advantage of being flexible, having long range, and high data capability. It also operates in both licensed and unlicensed bands. This is unlike the Wi-Fi technology with a limited range data capacity. The analysis carried out also indicated that while the path loss experienced in both Wi-Fi and WiMax networks do increase with distance of signal coverage, it decreases with transmitting antenna height. Hence, when a correct mix is ensured in choosing the distance of signal transmission and the antenna height, an optimum call handover is guaranteed in $\mathrm{Wi}-\mathrm{Fi}$ and WiMax networks. Thus, with proper design parameters, a good network environment could be created that allow mobile subscribers move around the network sharing information with improved services and wireless proficiency. Future work will focus on the use of linear regression analysis to model the relationship between the distance of coverage (d) of a Wifi /WiMax network to the signal degradation or pathloss (PL). This will enable the determination of pathloss coefficient/exponent for the selected testbed

\section{ACKNOWLEDGMENTS}

The authors wish to appreciate Addax-Sinopec Petroleum, Globacom Nigeria and Kswitche Consults who have contributed towards development of the research through their testbed equipment.

\section{REFERENCES}

[1] S.Banerji, Rahul Singha C. 2013. IEEE 802.11: Wireless LAN Technology, International Journal of Mobile Network Communications \& Telematics (IJMNCT) Vol. 3, Issue. 4, 2013. [DOI: 10.5121/ijmnct.2013.3405]

[2] Nashiry, A., Mahmud, A. A., Rahman, M., Anjum, N., (2008),"Evaluation of TCP Performance over Mobile IP Wired-cum-Wireless Networks,"

[3] Mohammad Siraj \& Soumen Kanrar ,Performance of Modeling wireless networks in realistic environment, International Journal of Computer Networks (IJCN), Volume (2): Issue (1),pp.62-79.

[4] Mohanty S and Akyildiz I F,(2003) "An Architecture and Associated Protocols for Inter-System Handover between $3 \mathrm{G}$ and WLAN,".

[5] Rong-Biao Zhang, Jian-Guang Guo*, Fu-Huan Chu, YeCheng Zhang, “, Environmental-adaptive indoor radio path loss model for wireless sensor networks localization, In Int. J. Electron. Commun. (AEÜ) 65 (2011) 1023- 1031. Elseiver Sciemce Direct.

[6] Mao GQ, Fidan B, Anderson BDO. Wireless sensor network location techniques. Computer Networks 2007;51:2529-53.

[7] Liu H, Darabi HS, Banerjee P, Liu J. 2007. Survey of wireless indoor positioning techniques and systems. IEEE Transactions on Systems, Man, and Cybernetics, Part C: Applications and Reviews 2007;37(6):1067-80.

[8] He T, Huang CD, Blum BM, Stankovic JA, Abdelzaher TF 2003.. Range-free localization schemes in large scale sensor. In: Proceedings of MOBICOM. 2003. p. 81-95.

[9] Tian S, Zhang XM, Liu PX, Sun P, Wang XG. A RSSIbased DV-Hop algorithm forwireless sensor networks. In: Proceedings of International Conference on Wireless Communications, Networking and Mobile Computing. 2007. p. 2555-8.

[10] Tian JP, Shi HC, Guo WL, Zhou YF. 2008. A RSSIbased location system in coal mine. In: Proceedings of International Conference on 2008 China-Japan Joint Microwave.2008. p. 167-71. 
[11] Barsocchi P, Lenzi S, Chessa S, Giunta G. A novel approach to indoor RSSI localization by automatic calibration of the wireless propagation model. In: Proceedings of the 69th IEEE Vehicular Technology Conference (VTC). 2009. p.1-5.

[12] Jin RC, Wang HB, Peng B, Ge N. Research on RSSIbased localization in wireless sensor networks. In: Proceedings of the 4th International Conference on Wireless Communications, Networking and Mobile Computing (WiCOM’08). 2008. p. 1-4.

[13] Friedman J, Charbiwala Z, Schmid T, Cho Y, Srivastava M. Angle-of-arrival assisted radio interferometry (ARI) target localization. In: Proceedings of the IEEE Military Communications Conference. 2008. p. 1-7.

[14] Boushaba M, Hafid A, Benslimane A. High accuracy localization method using AOA in sensor networks. Computer Networks 2009;53(18):3076-88.

[15] Gardner WA, Chen CK. Signal-selective timedifference-of-arrival estimation for passive location of man-made signal sources in highly corruptive environments. I. Theory and method. IEEE Transactions on Signal Processing 1992;40(5):1168-84.

[16] Ho KC, Xu WW. An accurate algebraic solution for moving source location using TDOA and FDOA measurements. IEEE Transactions on Signal Processing 2004; 52(9):2453-63.

[17] Wang X, Wang Z, O'Dea B. A TOA-based location algorithm reducing the errors due to non-line-of-sight (NLOS) propagation. IEEE Transactions on Vehicle Technology 2003; 52:112-6.

[18] Romer K. The lighthouse location system for smart dust. In: Proceedings of the 1st International Conference on Mobile Systems, Applications and Services. 2003. p. 1530.

[19] Gezici S, Tian Z, Giannakis G, Kobayashi H, Molisch A, Poor H, Sahinoglu Z. Localization via ultra wide band radios: a look at positioning aspects for future sensor networks. IEEE Signal Processing Magazine 2005;22(4):70-84.
[20] Milanovic, J., Rimac-Drlje, S., Bejuk, K.: Comparison of Propagation Models Accuracy for WiMax on $3.5 \mathrm{GHz}$ ". IEEE conference, pp. 111-114, (2007).

[21] COST Action 231 1999. Digital Mobile Radio : Towards Future generation systems. Final report, Tech. Report. European Communities, EUR 18957, Ch. 4.

[22] Hata, M. 1980. Empirical formula for propagation loss in land mobile radio services. IEEE Transactions on Vehicular Technology, VT-29(3), pp. 317-325.

[23] Ikegami, F., Yoshida, S., Tacheuchi, T. and Umehira, M. 1984. Propagation Factors controlling Mean Field Strength on Urban Streets, IEEE Trans., AP32(8), 822829.

[24] Lee W.C.Y, Estimate of Local Average Power of a Mobile Radio Signal, IEEE Transactions. Vehicular. Technology, 34, 1985, 22-27.

[25] Md. Didarul Alam and Md. Rezaul Huque Khan, “ Comparative Study of Path Loss Models of WiMax at $2.5 \mathrm{GHz}$ Frequency Band, International Journal of Future Generation Communication and Networking Vol. 6, No. 2, April, 2013.

[26] Chhaya Dalela, “ Propagation Path Loss Modeling for Deployed WiMax Network, "In International Journal of Emerging Technology and Advanced Engineering Vol. 2, Issue 8, August 2012, pp.172-176.

[27] Isabona Joseph, Konyeha. C.C, “Area Path loss Propagation Prediction and Optimisation Using Hata Model at $800 \mathrm{MHz} "$, IOSR Journal of Applied Physics (IOSR-JAP). Volume 3, Issue 4 (Mar. - Apr. 2013), PP $08-18$.

[28] Pratibha Maina ,Gopal Chandra Manna, Namrata Sahayam, Validation Study Of Path Loss Models On WiMax At 2.6 Ghz Frequency Band In"Suburban Environment For Cell Size Planning", International Journal of Next-Generation Networks (IJNGN) Vol.6, No.2, June 2014, DOI : 10.5121/ijngn.2014.6202 17. 